\title{
Haemophilus influenzae serotype B (Hib) seroprevalence in England and Wales in 2009
}

S N Ladhani (shamez.ladhani@hpa.org.uk) ${ }^{1}$, M E Ramsay' ${ }^{1}$ J S Flood ${ }^{1}$, H Campbell ${ }^{1}$, M P Slack ${ }^{1}$, R Pebody ${ }^{1}$, J Findlow ${ }^{2}$, E Newton ${ }^{2}$, M Wilding ${ }^{2}$, R Warrington ${ }^{2}$, H Crawford ${ }^{2}$, S Y Min ${ }^{2}$, K Gray $^{2}$, S Martin ${ }^{2}$, S Frankland ${ }^{2}$, N Bokuvha ${ }^{2}$, G Laher $^{2}$, R Borrow $^{2}$

1. Health Protection Agency Colindale, London, United Kingdom

2. Vaccine Evaluation Unit, Health Protection Agency, Manchester Medical Microbiology Partnership, Manchester Royal Infirmary, Manchester, United Kingdom

Ladhani SN, Ramsay ME, Flood JS, Campbell H, Slack MP, Pebody R, Findlow J, Newton E, Wilding M, Warrington R, Crawford H, Min SY, Gray K, Martin S, Frankland S, Bokuvha N, Laher G, Borrow R. Haemophilus influenzae serotype B (Hib) seroprevalence in England and Wales in 2009. Euro Surveill. 2012;17(46):pii=20313. Available online: http://www.eurosurveillance.org/ViewArticle. aspx?Articleld=20313

Article submitted on 19 April 2012 / published on 15 November 2012

A national seroprevalence study was performed to determine the prevalence of Haemophilus influenzae type $\mathrm{b}$ (Hib) antibodies in England and Wales in 2009, when Hib disease incidence was the lowest ever recorded. A total of 2,693 anonymised residual sera from routine diagnostic testing submitted by participating National Health Service hospital laboratories were tested for Hib anti-polyribosyl-ribitol phosphate (PRP) IgG antibodies using a fluorescent bead assay. Median anti-PRP IgG concentrations were highest in toddlers aged 1-4 years $(2.65 \mu \mathrm{g} / \mathrm{ml})$, followed by children aged 5-9 years $(1.95 \mu \mathrm{g} / \mathrm{ml})$. Antibody concentrations were significantly lower after this age, but were still significantly higher among 10-19 year-olds (0.54 $\mu \mathrm{g} / \mathrm{ml})$ compared with adults aged $>20$ years $(0.16 \mu \mathrm{g} /$ $\mathrm{ml}$; p 0.0001$)$. Half of the adults ( $51 \%)$ did not have Hib antibody concentrations $\geq 0.15 \mu \mathrm{g} / \mathrm{ml}$, the level considered to confer short-term protection. Thus, the current excellent Hib control appears to be the result of high anti-PRP antibody concentrations in children aged up to 10 years, achieved through the various childhood vaccination campaigns offering booster immunisation. The lack of seroprotection in adults emphasises the importance of maintaining control of the disease and, most probably carriage, in children, therefore raising the question as to whether long-term routine boosting of either pre-school children or adolescents may be required.

\section{Introduction}

The incidence of invasive Haemophilus influenzae type b (Hib) disease in England and Wales is currently the lowest ever recorded in both children and adults [1]. Conjugate vaccines against $\mathrm{Hib}$ are highly effective in preventing invasive disease [2]. The United Kingdom (UK) introduced the Hib conjugate vaccine into the national childhood immunisation programme in October 1992. Unlike most other countries, the UK initially opted for a three dose infant schedule at two, three and four months of age without a booster in the second year of life. Instead, a catch-up campaign offering two doses of the vaccine to infants aged 8-11 months and one dose to toddlers aged up to four years was performed during 1992-93 [1]. Hib cases declined rapidly such that, in children aged $<5$ years, the annual number of reported cases in England and Wales fell from almost 500 in the pre-vaccine era to around 20 within two years of vaccine implementation [1]. In 1998, the vaccine failure rate, derived from the observed number of true vaccine failures and the vaccine coverage in the eligible cohorts, was estimated at 2.2 per 100,000 vaccinees (95\% confidence interval: 1.8-2.7 per 100,000) [3]. In addition, because conjugate vaccines also reduce the acquisition of carriage and young children have the highest carriage rates [1], cases in older children and adults also declined through indirect (herd) protection [4].

From 1999, however, the number of invasive Hib cases started to increase in all age groups, but particularly in toddlers aged 1-4 years [1]. Reasons for this increase included a decline in indirect protection offered by the 1992 catch-up campaign over time [4], lower than predicted long-term protection in children who were vaccinated in infancy [5] and a temporary change to a less immunogenic acellular pertussis-containing combination Hib conjugate vaccine (DTaP-Hib) used during 2000-01 [6].

In response to this increase, the DTaP-Hib preparation was replaced with a more immunogenic whole-cell pertussis-containing combination Hib conjugate vaccine (DTwP-Hib) from 2002, and subsequently with a DTaPHib-IPV vaccine with better Hib immunogenicity from 2004. A booster campaign was subsequently undertaken in 2003 to provide an extra dose of Hib vaccine to the cohort of children (born between April 1999 and March 2003) who may have received the less immunogenic DTaP-Hib conjugate vaccine in infancy. This was followed in 2006 by the introduction of a routine 12-month Hib-Meningococcal serogroup C (Hib-MenC) combination booster into the national childhood immunisation schedule. Additionally, in 2007, following an increase in cases in certain birth cohorts during 2005 and 2006, a pre-school booster dose of a Hib containing vaccine was offered to those born between March 
2003 and September 2005. This cohort would have been too young for the 2003 booster campaign and too old for the routine 12-month booster. Together, these measures have, once again, resulted in a decline in the incidence of invasive Hib disease among both children and adults such that there were only 37 reported cases in 2009, mainly in adults (26 cases) [7].

In 2010, the Health Protection Agency (HPA) undertook a seroprevalence study to assess population immunity against Hib in 2009 by measuring antibodies against the Hib polysaccharide capsule across age groups in order to help explain the excellent control of invasive Hib disease, to identify potential susceptible cohorts and to help guide future national Hib vaccination policies.

\section{Methods}

\section{Serum samples}

Participating laboratories submit residual sera from routine diagnostic testing to the HPA Sero-epidemiology Unit (SEU). All samples are anonymised, a unique identity number is assigned and details of age, sex, date of sample collection and geographic location are collated on a database.

For this study, a total of 2,693 sera were selected for infants aged 6-11 months $(n=104)$, toddlers aged $1-4$ years ( $n=653), 5-14$ year-olds ( $n=990), 15-24$ year-olds $(n=343), 25-44$ year-olds $(n=301), 45-64$ year-olds $(n=121)$ and $\geq 65$ year-olds $(n=181)$ from the HPA SEU as described by Osborne et al. [8]. Antibody concentrations (IgG) against the Hib capsular polysaccharide (polyribosyl-ribitol phosphate (PRP)) were quantified using a fluorescent bead assay as described previously [9]. Briefly, PRP was conjugated to carboxylated microspheres (Luminex Corporation; Texas, United States) following bead activation (via a two-step carbodiimide reaction). Serum was diluted 1:100 and a standard curve prepared using the World Health Organization (WHO) international standard TE-3. Diluted preparations were added to a filter plate (Millipore, Watford, UK) and mixed with conjugated beads. Following incubation, the plate was washed and anti-human IgG-RPhycoerythrin (RPE) added to each well. Following incubation and washing, the plate was read on a BioPlex workstation (BioRad, Hertfordshire, UK) and analysis undertaken using Bioplex manager software, with a four parameter logistic fit model.

\section{Definitions}

The thresholds for short-term and long-term protection against invasive Hib disease are based on previous animal experiments, studies on natural immunity, passive immunisation and the original clinical trials of Hib-PRP polysaccharide vaccines, which suggested that minimum anti-PRP IgG concentrations of $0.05-0.15$ $\mu \mathrm{g} / \mathrm{ml}$ at the time of exposure to the organism were required to protect against invasive disease $[10,11]$. Therefore, anti-PRP antibody concentrations $\geq 0.15 \mu \mathrm{g} /$ $\mathrm{ml}$ were considered to confer short-term protection $[12,13]$, while concentrations $\geq 1 \mu \mathrm{g} / \mathrm{ml}$ would ensure a minimum concentration of $0.1 \mu \mathrm{g} / \mathrm{ml}$ after 12 months, thereby conferring long-term protection [10]. Anti-PRP IgG concentrations $\geq 5.0 \mu \mathrm{g} / \mathrm{ml}$ were considered to confer protection against acquisition of Hib carriage $[14,15]$.

\section{Data analysis}

Data for anti-PRP IgG concentrations were initially analysed by age group of individuals at the time of serum collection in 2009 and compared with raw data from previous seroprevalence studies which utilised the same source of samples $[4,16]$. The data from these previous seroprevalence studies, which analysed sera from 1993 to 2001, were grouped into two time periods: (i) 1993-94, when the Hib conjugate vaccine had recently been introduced into the national childhood immunisation programme; and (ii) 1995-2001, when routine infant Hib conjugate vaccination was in place.

Subsequently, data from individuals aged $<25$ years in this 2009 seroprevalence study were categorised and analysed by birth cohorts eligible for different Hib vaccination, catch-up and booster programmes. Anti-PRP IgG concentrations for adults aged $\geq 25$ years, who would not have been eligible for Hib conjugate vaccination at any time, were included for comparison. As anti-PRP IgG results were highly skewed and not normally distributed even when log-transformed, median values with interquartile ranges (IQR) are reported and compared using the Mann-Whitney U test. Categorical variables are expressed as proportions and compared using the chi-squared test. Trends in median anti-PRP concentrations and proportion achieving Hib antibody concentrations above specified thresholds over the three surveillance studies were assessed using the non-parametric test for trend and the chi-squared test for trend, respectively.

\section{Ethical approval}

National Research Ethics Service (NRES) approval for the sero-epidemiological surveillance of the National Immunisation programme of England and Wales (Research Ethics Committee number 05/Q0505/45) was granted by the Joint University College London/ University College London Hospital (UCL/UCLH) Committees on the Ethics of Human Research.

\section{Results}

In 2009, median anti-PRP IgG concentrations in children were highest among toddlers aged $1-4$ years $(2.65$ $\mu \mathrm{g} / \mathrm{ml} ;$ IQR: 0.68-9.39), and significantly higher than in children aged $5-9$ years $(1.95 \mu \mathrm{g} / \mathrm{ml}$; IQR: 0.49-6.25; $\mathrm{p}=0.0063$ ) (Figure 1). Antibody concentrations in both age groups were significantly ( $p<0.01$ ) higher in 2009 compared with the 1993-94 and 1995-2001 seroprevalence periods. After this age, the 2009 seroprevalence study shows that antibody concentrations declined, but were still significantly higher among adolescents of 10-19 years-old (who would have been vaccinated 


\section{FIGURE 1}

Comparison by age group of the results of three Haemophilus influenzae serotype B seroprevalence studies, England and Wales, 1993-2009
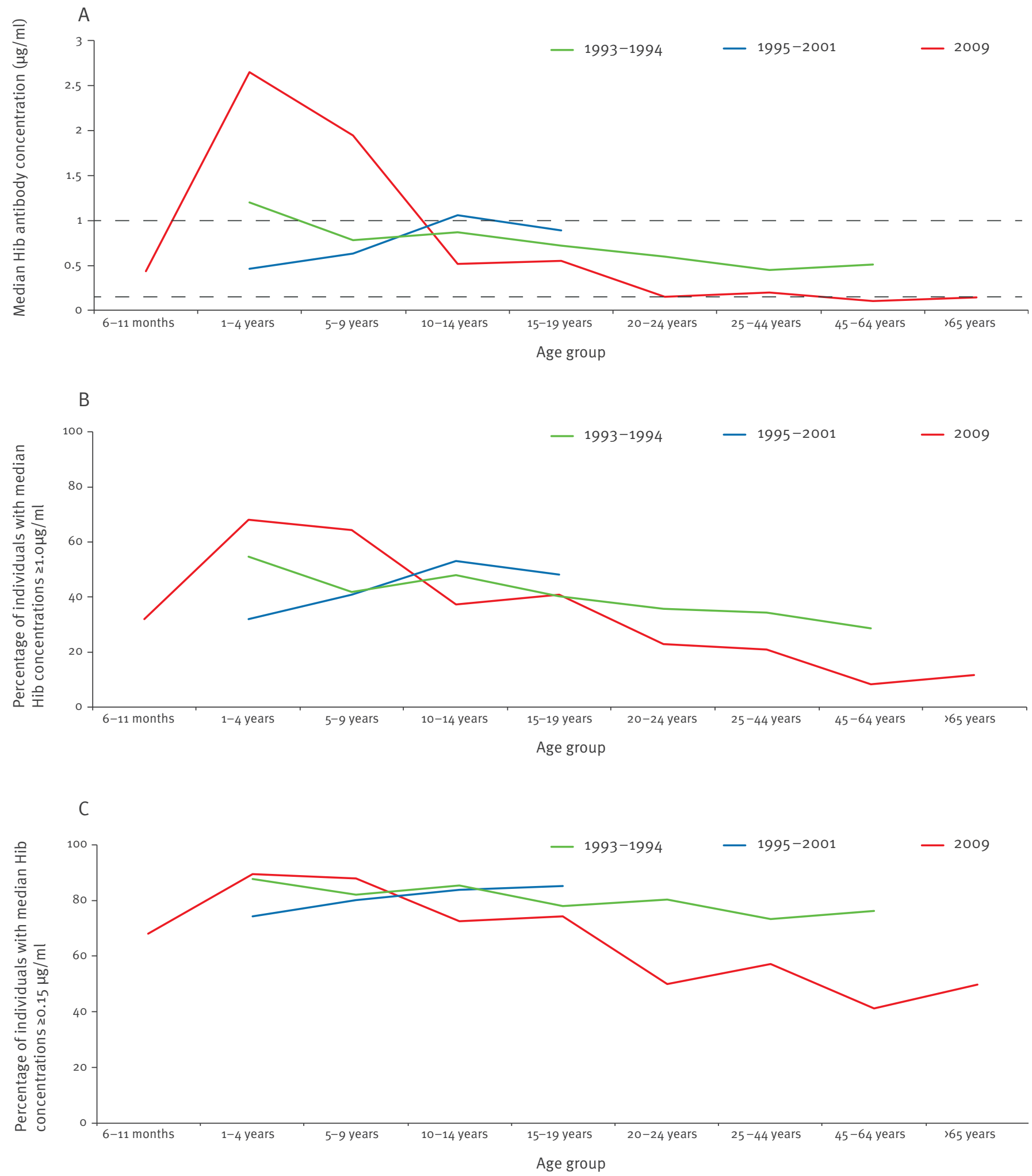

Hib: Haemophilus influenzae serotype B.

Hib antibody refers to Hib anti-polyribosyl-ribitol phosphate (PRP) IgG antibody. Hib antibody concentrations $\geq 0.15 \mu \mathrm{g} / \mathrm{ml}$ and $\geq 1.0 \mu \mathrm{g} / \mathrm{ml} \mathrm{refer}$ to the putative levels considered as respectively providing short-term and long-term protection against invasive Hib disease.

A. Median Hib antibody serum concentration by age group according to each seroprevalence study.

B. Percentage of individuals with Hib antibody concentrations $\geq 1.0 \mu \mathrm{g} / \mathrm{ml}$, by age group according to each seroprevalence study.

C. Percentage of individuals with Hib antibody concentrations $\geq 0.15 \mu \mathrm{g} / \mathrm{ml}$, by age group according to each seroprevalence study. 
Median Haemophilus influenzae serotype B antibody concentrations in the vaccinated cohort up to 20 years of age, seroprevalence study, England and Wales, 2009

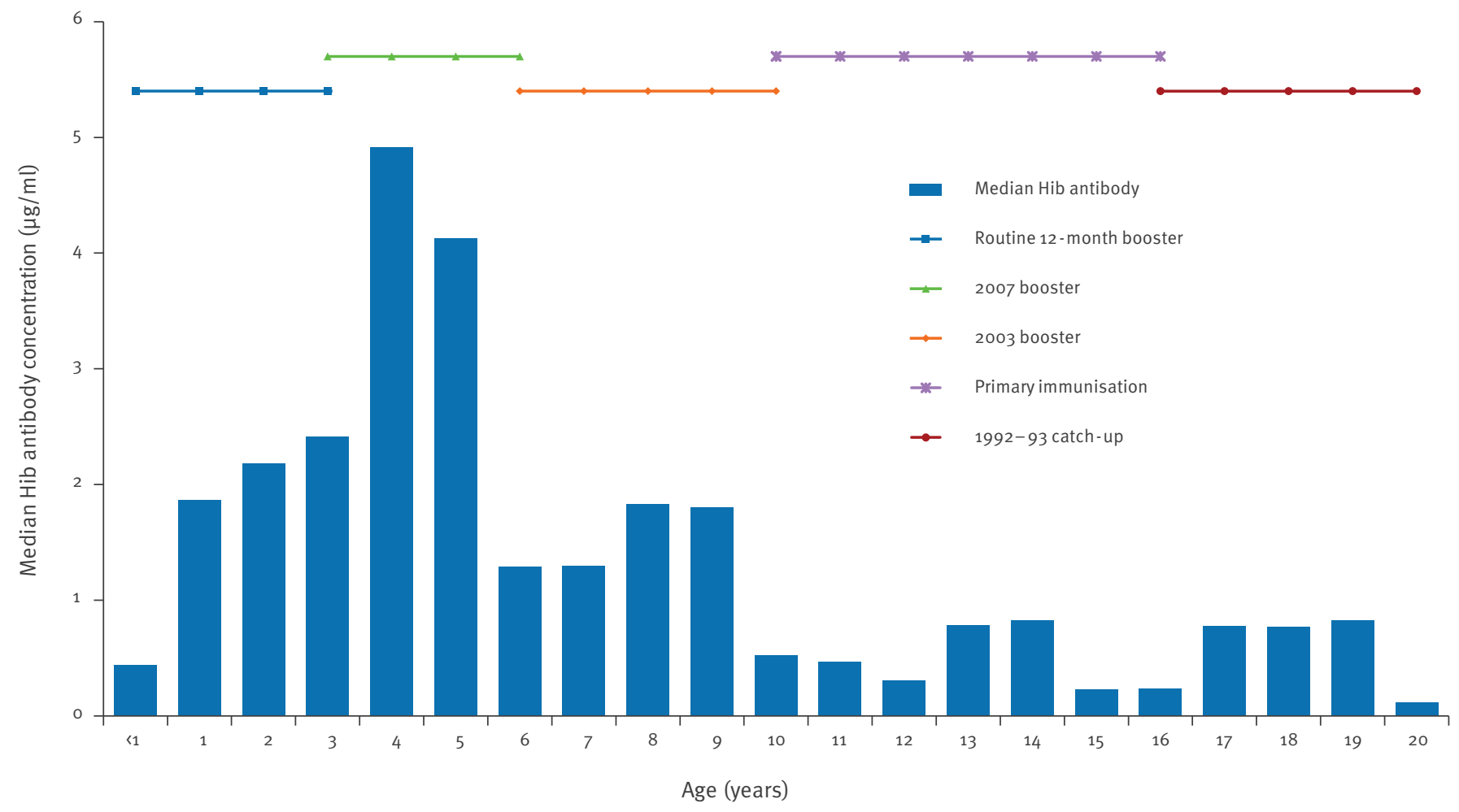

Hib: Haemophilus influenzae serotype B.

Hib antibody refers to Hib anti-polyribosyl-ribitol phosphate (PRP) IgG antibody. The horizontal bars denote birth cohorts receiving different vaccination schedules (Table 1).

against Hib in early childhood) compared with older, mostly unvaccinated adults (median: $0.54 \mu \mathrm{g} / \mathrm{ml}$; IQR: 0.13-2.58 vs. $0.16 \mu \mathrm{g} / \mathrm{ml}$; IQR: 0.05-0.55; p<0.0001). Anti-PRP IgG concentrations among 10-19 year-olds in 2009 were comparable to the 1993-94 and 1995-2001 cohorts, with $>70 \%$ and $>40 \%$ in the three surveillance periods having antibody concentrations consistent with short-term protection ( $\geq 0.15 \mu \mathrm{g} / \mathrm{ml}$ ) and long-term protection $(\geq 1.0 \mu \mathrm{g} / \mathrm{ml})$, respectively. This compares with $89 \%(542 / 606)$ and $68 \%(413 / 606)$ of toddlers having anti-PRP concentrations $\geq 0.15 \mu \mathrm{g} / \mathrm{ml}$ and $\geq 1.0$ $\mu \mathrm{g} / \mathrm{ml}$, respectively, in 2009.

Subsequent analysis of anti-PRP IgG concentrations in 2009 by birth cohort showed the highest anti-PRP IgG concentrations in those eligible for the 2007 pre-school booster campaign targeting children who had been too young for the 2003 booster campaign and too old for the routine 12 month booster introduced in September 2006 (Figure 2, Table 1). The 1992 catch-up cohort that was eligible for the Hib conjugate vaccine as toddlers in 1992-93 had median anti-PRP IgG concentrations of $1.54 \mu \mathrm{g} / \mathrm{ml}$ (IQR: $0.61-7.28, \mathrm{n}=102$ tested) at three years of age and $1.36 \mu \mathrm{g} / \mathrm{ml}$ (IQR: $0.34-4.38, \mathrm{n}=108$ tested) at four years of age in the 1993-94 seroprevalence study. This compared with $4.49 \mu \mathrm{g} / \mathrm{ml}$ (IQR: 1.31-18.5, $\mathrm{n}=34$ tested) and 4.92 $\mu \mathrm{g} / \mathrm{ml}$ (IQR: 0.87-18.9, $\mathrm{n}=134$ tested) for the same ages, respectively, who had been eligible for the 2007 booster campaign and were tested in the 2009 seroprevalence study.

In two cohorts eligible for the same immunisation schedule (those eligible for primary immunisation in 1992-93 and toddlers who were part of the 1992 catchup campaign) median antibody concentrations during all three surveillance periods were compared and showed significant declining trends (Table 2). Waning of antibodies with age was also demonstrated for children eligible for the same immunisation schedule. In children aged 1-5 years who were born during 1995-99 and, therefore, eligible for the primary immunisation schedule and tested in $2000(n=414$ tested), median $\mathrm{Hib}$ antibody concentrations fell from $0.88 \mu \mathrm{g} / \mathrm{ml}$ (IQR: $0.30-3.24$ ) among one year-olds to $0.40 \mu \mathrm{g} / \mathrm{ml}$ (IQR: $0.16-0.95)$ among five year-olds $(p=0.02)$. The proportion with anti-PRP antibody concentrations $\geq 1.0 \mu \mathrm{g} / \mathrm{ml}$ declined similarly from $47 \%$ ( $41 / 88$ cases) to $24 \%$ ( $9 / 37$ cases), respectively $(p=0.015)$. 
TABLE 1

Hib antibody concentrations and proportion of individuals with distinct protective antibody concentration levels in unvaccinated age groups and in birth cohorts eligible for different Hib immunisation programmes respectively, England and Wales, 2009 ( $n=2,411$ samples)

\begin{tabular}{|c|c|c|c|c|c|c|c|}
\hline \multirow{2}{*}{$\begin{array}{l}\text { Group } \\
\text { description }\end{array}$} & \multirow{2}{*}{$\begin{array}{l}\text { Birth dates }^{\mathrm{a}} \text { (age } \\
\text { range of serum } \\
\text { donors in years }{ }^{\mathrm{b}} \text { ) }\end{array}$} & \multirow{2}{*}{ Description } & \multirow{2}{*}{$\begin{array}{l}\text { Number of } \\
\text { samples } \\
\text { tested }\end{array}$} & \multirow{2}{*}{$\begin{array}{l}\text { Median Hib } \\
\text { antibody } \\
\text { concentration in } \\
\mu \mathrm{g} / \mathrm{ml}(\mathrm{QQR})\end{array}$} & \multicolumn{3}{|c|}{$\begin{array}{c}\text { Number of samples n (\%) with Hib } \\
\text { antibody concentrations }\end{array}$} \\
\hline & & & & & $\geq 0.15 \mu \mathrm{g} / \mathrm{ml}$ & $\geq 1.0 \mu \mathrm{g} / \mathrm{ml}$ & $\geq 5.0 \mu \mathrm{g} / \mathrm{ml}$ \\
\hline $\begin{array}{l}\text { Cohort having } \\
\text { primary } \\
\text { immunisation } \\
\text { with no } \\
\text { booster }\end{array}$ & $\begin{array}{c}\text { O1 August } \\
1992-01 \text { April } \\
1999(9.9-16.3)\end{array}$ & $\begin{array}{l}\text { Hib conjugate vaccine was } \\
\text { first offered to all UK infants } \\
\text { on } 01 \text { October } 1992 \text { at a } \\
\text { two, three and four month } \\
\text { schedule }\end{array}$ & 319 & $0.42(0.11-2.45)$ & $226(71)$ & $112(35)$ & $44(14)$ \\
\hline $\begin{array}{l}\text { Cohort with } \\
\text { 1992-93 } \\
\text { catch-up }\end{array}$ & $\begin{array}{c}\text { O1 August } \\
1988-31 \text { July } \\
1992(16.3-20.5)\end{array}$ & $\begin{array}{l}\text { With the introduction of } \\
\text { infant Hib vaccination in } \\
\text { 1992, a 12-month catch-up } \\
\text { campaign targeting all } \\
\text { children up to four years-old } \\
\text { was initiated }\end{array}$ & 146 & $0.59(0.13-2.40)$ & $106(73)$ & $60(41)$ & $24(16)$ \\
\hline $\begin{array}{l}\text { Cohort with } \\
2003 \text { booster }\end{array}$ & $\begin{array}{l}02 \text { April } 1999-12 \\
\text { March 2003 } \\
(6.0-10.3)\end{array}$ & $\begin{array}{l}\text { Between May and September } \\
2003 \text {, the birth cohort most } \\
\text { likely to have received the } \\
\text { less immunogenic DTaP- } \\
\text { Hib vaccine in infancy was } \\
\text { offered an extra dose of Hib } \\
\text { vaccine }\end{array}$ & 531 & $1.62(0.46-5.30)^{c}$ & $464(87)^{c}$ & $328(62)^{c}$ & $141(27)^{c}$ \\
\hline $\begin{array}{l}\text { Cohort } \\
\text { with } 2007 \\
\text { pre-school } \\
\text { booster }\end{array}$ & $\begin{array}{l}13 \text { March } 2003^{-} \\
03 \text { September } \\
2005\left(3.4^{-6.5}\right)\end{array}$ & $\begin{array}{l}\text { Children who were too young } \\
\text { to be eligible for the } 2003 \\
\text { booster campaign and too } \\
\text { old for the } 12 \text {-month routine } \\
\text { booster were offered an extra } \\
\text { dose of Hib vaccine as part of } \\
\text { their pre-school vaccination }\end{array}$ & 375 & $3.80(0.81-12.8)^{c}$ & $333(89)^{c}$ & $271(72)^{c}$ & $165(44)^{c}$ \\
\hline $\begin{array}{l}\text { Cohort with } \\
2006 \text { routine } \\
\text { booster }\end{array}$ & $\begin{array}{l}\text { 04 September } \\
2005-31 \\
\text { December } 2009 \\
\text { (0.5-4.1 years) }\end{array}$ & $\begin{array}{l}\text { Since } 04 \text { September } 2006 \text {, } \\
\text { all UK infants are offered a } \\
12 \text {-month routine Hib booster }\end{array}$ & 437 & $1.94(0.66-8.00)^{c}$ & $390(89)^{c}$ & $289(66)^{c}$ & $141(32)^{c}$ \\
\hline $\begin{array}{l}\text { Unvaccinated } \\
25-44 \\
\text { year-olds }\end{array}$ & NA (25-44.9) & Unvaccinated population & 301 & $0.20(0.07-0.80)^{c}$ & $172(57)^{c}$ & $63(21)^{c}$ & $15(5)^{c}$ \\
\hline $\begin{array}{l}\text { Unvaccinated } \\
45-64 \\
\text { year-olds }\end{array}$ & NA $(45.0-64.7)$ & Unvaccinated population & 121 & $0.10(0.02-0.38)^{c}$ & $50(41)^{c}$ & $10(8)^{c}$ & $3(2)^{c}$ \\
\hline $\begin{array}{l}\text { Unvaccinated } \\
\geq 65 \text { year-old }\end{array}$ & NA $(65.0-85.0)$ & Unvaccinated population & 181 & $0.15(0.02-0.39)^{c}$ & $90(50)^{c}$ & $21(12)^{c}$ & $4(2)^{c}$ \\
\hline
\end{tabular}

DTaP-Hib: acellular pertussis-containing combination Hib conjugate vaccine; Hib: Haemophilus influenzae serotype B; IQR: interquartile range; NA: not applicable; UK: United Kingdom.

Hib antibody refers to Hib anti-polyribosyl-ribitol phosphate (PRP) IgG antibody. Hib antibody concentrations $\geq 0.15, \geq 1.0$ and $\geq 5.0 \mu g / m l$ refer respectively to the putative levels considered to confer short-term protection, long-term protection and protection against carriage.

a Birth dates define the cohorts eligible for the different Hib immunisation programmes and are, therefore, not applicable to unvaccinated adults.

b The serum donor age is the age of the donor at the time serum is collected. The age range of serum donors for the different cohorts may overlap because sera were obtained throughout the 2009 calendar year.

p<0.001 when compared to respective values from individuals who only received primary immunisation as infants with no booster.

d Only data from children aged $\geq 12$ months were presented for this cohort in order to compare median Hib antibody concentrations and respective proportions of individuals with defined antibody concentrations to the values for individuals who only received primary immunisation with no booster. 
In the 2009 seroprevalence study, the cohort eligible for the 2007 pre-school booster was more likely to have very high anti-PRP IgG concentrations than the cohort eligible for the booster in 2003 (given between 6 months and 4 years of age) and those eligible for a booster at 12 months of age after 2006. Forty four per cent $(165 / 375)$ of children in the pre-school cohort achieved concentrations $\geq 5 \mu \mathrm{g} / \mathrm{ml}$ (the putative level considered to prevent acquisition of Hib carriage), compared with $27 \%(141 / 531 ;$ p $<0.001)$ and $32 \%(141 / 437$; $p=0.001)$ of the 2003 booster cohorts and the 2006 routine 12-month booster cohort, respectively (Table 1). These findings were similar when comparing median anti-PRP IgG antibody concentrations (Figure 2, Table 1). Among children aged $\geq 12$ months in the cohort eligible for a routine 12-month Hib booster, the median concentration was $1.94 \mu \mathrm{g} / \mathrm{ml}$ (IQR: $0.66-8.00$ ), with $89 \%$ (309/437) and 66\% (289/437) achieving concentrations $\geq 0.15 \mu \mathrm{g} / \mathrm{ml}$ and $\geq 1.0 \mu \mathrm{g} / \mathrm{ml}$, respectively. This cohort would have been vaccinated more recently compared with those vaccinated during 2003 and 2007 booster campaigns. Older children and young adults who would have been eligible for the 1992 primary immunisation and catch-up campaign had substantially lower anti-PRP IgG concentrations in 2009, but these were still higher than older, unvaccinated adults ( $\geq 25$ years of age) (Table 1 ).

In adults, anti-PRP IgG concentrations in 2009 are the lowest since routine Hib immunisation was introduced (Figure 1). The median antibody concentration among adults aged $\geq 20$ years was $0.16 \mu \mathrm{g} / \mathrm{ml}$ (IQR: $0.05-0.55$ ), with only $51 \%(388 / 755)$ and $17 \%(129 / 755)$ achieving concentrations $\geq 0.15$ and $\geq 1.0 \mu \mathrm{g} / \mathrm{ml}$, respectively. These values are significantly lower than for the same age group in 1993-94, where the median anti-PRP IgG concentration was $0.57 \mu \mathrm{g} / \mathrm{ml}$ (IQR: 0.18-1.46; p $<0.0001)$, and $77 \%(150 / 195)$ (p<0.0001) and $35 \%$ (68/195) ( $p<0.0001)$ achieved concentrations $\geq 0.15 \mu \mathrm{g} /$ $\mathrm{ml}$ and $\geq 1.0 \mu \mathrm{g} / \mathrm{ml}$, respectively. Among adults aged 30-39 years, the median anti-PRP IgG concentration in 151 samples tested was $0.24 \mu \mathrm{g} / \mathrm{ml}$ (IQR: 0.06-0.96), with $59 \%(89 / 151)$ and $25 \%(37 / 151)$ achieving concentrations $\geq 0.15$ and $\geq 1.0 \mu \mathrm{g} / \mathrm{ml}$, respectively. This compares with median anti-PRP IgG antibody concentrations $(\mu \mathrm{g} / \mathrm{ml})$ in the same age group of 1.29 in 1991 (pre-vaccine), 0.70 in 1994 (2 years after vaccine introduction), 0.53 in 1997 (time of excellent Hib control), 0.69 in 2000 (beginning of Hib resurgence) and 0.77 in 2002 (middle of Hib resurgence) [4].

\section{TABLE 2}

Demonstration of waning of Hib antibody over time in two birth cohorts for which seroprevalence was assessed over 1993-94, 1995-2001 and 2009 periods, England and Wales (n=956 samples)

\begin{tabular}{|c|c|c|c|c|c|}
\hline & & \multicolumn{3}{|c|}{ Seroprevalence periods } & \multirow{2}{*}{ Significance $^{a}$} \\
\hline & & $1993-94$ & $1995-2001$ & 2009 & \\
\hline \multirow{3}{*}{$\begin{array}{l}\text { Primary immunisation } \\
\text { schedule (birth cohort: } 01 \\
\text { August 1992-31 July 1993) }\end{array}$} & $\begin{array}{c}\text { Median Hib antibody } \\
\text { concentration in } \mu \mathrm{g} / \mathrm{ml}(\mathrm{IQR})\end{array}$ & $0.65(0.33-3.3)$ & $0.63(0.19-2.0)$ & $0.23(0.05-3.6)$ & $p=0.006$ \\
\hline & $\begin{array}{l}\text { Proportion of samples tested (\%) } \\
\text { with Hib antibody } \\
\text { concentrations } \geq 0.15 \mu \mathrm{g} / \mathrm{ml}\end{array}$ & $87 / 99$ (88) & $133 / 166(80)$ & $30 / 44(68)$ & $p=0.006$ \\
\hline & $\begin{array}{l}\text { Proportion of samples tested } \\
\text { with Hib antibody } \\
\text { concentrations } \geq 1.0 \mu \mathrm{g} / \mathrm{mL}\end{array}$ & 44/99 (44) & $62 / 166(37)$ & $16 / 44(36)$ & $p=0.27$ \\
\hline \multirow{3}{*}{$\begin{array}{l}1992 \text { catch-up campaign } \\
\text { (birth cohort: 01 August } \\
\text { 1988-31 July 1992) }\end{array}$} & $\begin{array}{c}\text { Median Hib antibody } \\
\text { concentration in } \mu \mathrm{g} / \mathrm{ml}(\mathrm{IQR})\end{array}$ & $1.40(0.38-4.5)$ & $0.68(0.25-1.7)$ & $0.59(0.13-2.4)$ & $p<0.001$ \\
\hline & $\begin{array}{c}\text { Proportion of samples tested (\%) } \\
\text { with Hib antibody } \\
\text { concentrations } \geq 0.15 \mu \mathrm{g} / \mathrm{ml}\end{array}$ & $260 / 294(88)$ & $166 / 207(80)$ & $106 / 146(73)$ & $p<0.001$ \\
\hline & $\begin{array}{c}\text { Proportion of samples tested (\%) } \\
\text { with Hib antibody } \\
\text { concentrations } \geq 1.0 \mu \mathrm{g} / \mathrm{ml}\end{array}$ & $168 / 294(57)$ & $84 / 207(41)$ & $60 / 146(41)$ & $p<0.001$ \\
\hline
\end{tabular}

Hib: Haemophilus influenzae serotype B.

Hib antibody refers to Hib anti-polyribosyl-ribitol phosphate (PRP) IgG antibody. Hib antibody concentrations $\geq 0.15$, $\geq 1.0 \mu g / m l$ refer to the putative levels considered to confer short and long-term protection, respectively.

a Medians were compared using the non-parametric test for trend and proportions were compared using the chi-squared test for trend. 


\section{Discussion}

High post-immunisation antibody levels are considered the most important factor in preventing invasive Hib disease both at an individual and at the population level [17]. In England and Wales, Hib disease control is currently excellent [7] and vaccine coverage for both primary Hib immunisation (95-96\%) and the 12 -month booster (92-94\%) remains very high [18]. In 2009, anti-PRP IgG concentrations in children aged up to 10 years of age in England and Wales were the highest that have ever been observed. In this age group, the various booster campaigns have provided excellent antibody levels and it is likely that these children will remain protected for some time.

Unlike the plain polysaccharide vaccine, conjugate vaccines, which have been used in the UK since Hib conjugate vaccine was introduced into the national childhood immunisation programme, induce a T cell-dependent immune response that results in development of immunological memory [19] and, subsequently, production of high avidity antibodies on re-exposure to the antigen [20]. Mathematical modelling of the impact of the Hib conjugate vaccine in the UK, however, cautioned against over-reliance on immunological memory for protection. The lower than expected protection offered by immunological memory probably occurs because, even in those primed with conjugate vaccination, it can take several days to observe a detectable increase in antibody concentrations following infection or vaccination [21]. This delay is too late to protect against invasive infection following exposure to the pathogen which is thought to occur over a period of a few hours. On the other hand, the mathematical model emphasised the importance of maintaining high post-immunisation antibody titres [17], which would not only protect children against invasive disease but also help reduce carriage acquisition $[11,22]$ and, therefore, transmission to unvaccinated cohorts, particularly adults.

In 2009, median anti-PRP IgG concentrations in 10-19 year-olds were substantially lower than in younger children, although the vast majority had protective antibody concentrations $(\geq 0.15 \mu \mathrm{g} / \mathrm{ml}$ ). This age group would have been eligible for either the primary immunisation schedule recommended from 1992 onwards or the 1992-93 catch-up campaign. Although some of these adolescents would have been vaccinated almost two decades ago and there was evidence of waning of immunity with time, many of them still had detectable IgG concentrations which appear to be protective, since invasive Hib disease is rare in this cohort compared with older, unvaccinated adults.

Outside the vaccinated cohort, however, over half the adults did not have anti-PRP IgG concentrations considered to confer short-term protection against invasive Hib disease. The validity of these thresholds in unimmunised adults, however, has not been established. It is speculated that natural immunity is acquired following exposure through carriage, for example [17], which is likely to confer much broader protection through development of protective antibodies not only against the polysaccharide capsule (as would occur following vaccination) but also against other Hib surface proteins and antigens. As a consequence, it is possible that individuals may be protected against disease even if they have undetectable anti-PRP antibodies and functional antibody assays to measure bactericidal activity, might be more informative.

The Hib polysaccharide capsule, however, is considered to be the primary activator of the immune response against this pathogen, with evidence dating as far back as the 1930's of an inverse correlation between anti-PRP IgG levels and risk of invasive Hib disease [1]. Such antibodies have been shown to be bactericidal both in vitro and in vivo [23], as have antibodies developed after Hib polysaccharide vaccination [24]. Prior to routine Hib vaccination, too, the epidemiology of invasive Hib disease in infants and toddlers closely correlated with the level of transplacentally-acquired protective maternal IgG antibodies [1]. In adults, the importance of the relationship between anti-PRP antibody and exposure to Hib is suggested by the secular change in antibody levels associated with the initial decline in childhood Hib disease after 1992 followed by the resurgence after 1999 in the UK [4]. The increase in adult Hib cases, with annual number of cases reaching levels similar to that observed in the pre-vaccine era was associated with a decline in anti-PRP IgG among English adults aged 30-39 years following the introduction of routine Hib vaccination [4]. The most plausible explanation is that initial reduction in adult Hib cases after 1992 reduced carriage of the organism among vaccinated children and, therefore, reduced transmission to susceptible individuals, including adults. One consequence of this phenomenon, however, was that adults were less likely to be exposed to Hib and, therefore, had reduced opportunities for natural acquisition or boosting of immunity. This was subsequently predicted by mathematical modelling of Hib transmission in the UK [25]. In addition, the model did not support a role for natural antibodies derived from other colonising encapsulated bacteria that might cross-react against the Hib capsule and, therefore, serve to boost natural immunity against this organism [17].

The rise in adult cases following the Hib resurgence in children suggests that disease control relies strongly on induction of high antibody levels in children not only to provide long-term protection for the vaccinated children but also to reduce carriage and, therefore, transmission to others [4]. This observation is supported by the impact of the two childhood booster campaigns in 2003 and 2007, which resulted in re-establishment of disease control among adults, who were not subjected to any intervention [26]. The finding of such low antiPRP IgG levels among adults is, therefore, concerning. In 2009 and 2010, 26/37 and 23/30 of invasive Hib cases occurred in adults, respectively, with a relatively even distribution of cases among 25-44, 45-64 
and $\geq 65$ year-olds [7]. It is, therefore, imperative that Hib control through adequate childhood immunisation is maintained in order to protect the adult population who are currently more vulnerable than at any other time in the past two decades.

In addition to the 2003 and 2007 booster campaigns, the introduction of a routine 12-month Hib booster appears to have a positive impact on maintaining high anti-PRP IgG levels after one year of age. That median anti-PRP IgG concentrations are not as high when compared with the 2007 pre-school booster campaign suggests that receiving a Hib conjugate vaccine at an older age may provide more sustained protection against invasive Hib disease and, perhaps carriage, too. Whether the current routine 12-month Hib booster will be sufficient to maintain disease control in the longterm is difficult to assess given the added protection currently offered by the other two booster campaigns. Hib antibody responses to DTaP-Hib combination vaccines are known to be substantially lower than either DTwP-Hib vaccines [27] or Hib conjugate vaccines administered alone [28]. In the UK, infants now routinely receive Pediacel ( $\mathrm{DTa}_{5} \mathrm{P}$-IPV-Hib), which replaced the DTwP-Hib vaccine in September 2004 because it is less reactogenic and, as it contains inactivated polio virus, removes the risk of vaccine-associated paralytic poliomyelitis with oral polio vaccine [26]. This vaccine contains a different acellular pertussis component to that implicated in the increase in invasive Hib disease after 1999 [29]. Given that Hib antibodies decline at a relatively constant rate in infants and young children [30] and that, currently, opportunities for natural boosting of immunity through Hib exposure are likely to be rare (as suggested by the low anti-PRP IgG seroprevalence in adults), long-term protection essentially relies on the peak antibody response achieved after the 12-month routine booster.

Seroprevalence studies have an important role in describing immunity at a population level. Like all seroprevalence studies, the results must be interpreted with the knowledge of the source of the samples and the tests performed. In our study, anonymised serum samples were acquired from a national serosurvey resource that collects residual sera from participating National Health Service (NHS) hospital laboratories and, therefore, may not be representative of the general population. However, the large number of samples does allow comparison of seroprotection across age groups, including different birth cohorts eligible for specific immunisation schedules. Moreover, results can be compared with previously published seroprevalence studies, which had used the same similar sample sources.

In conclusion, the current excellent control of invasive Hib disease in the UK appears to be the result of high IgG levels in children up to 10 years, who were eligible for the 2003 and 2007 booster campaigns or the routine 12-month booster, although antibody levels in the latter cohort were not as high. As the cohorts protected by the two booster campaigns age, disease control will rely mainly on children receiving the routine 12 -month booster. This cohort will, therefore, require close monitoring to ensure that they sustain sufficiently high antibody levels not only to protect themselves but also to protect others through reduced transmission. The lack of seroprotection in adults emphasises the importance of maintaining good control in children. In the absence of natural boosting, this study raises the question as to whether long-term control across all ages may require routine boosting of either pre-school children or adolescents. Given the current excellent control of invasive Hib disease in children, further studies should also focus on risk factors for and strategies to prevent invasive Hib disease in adults.

\section{Acknowledgments}

The authors would like to thank participating laboratories for submitting serum samples to the sero-epidemiology unit.

Funding source statement

The authors confirm that this study did not receive any external funding.

Conflict of interest statement

SNL has performed contract research for the HPA and St. George's University of London on behalf of Pfizer, GSK and Novartis Vaccines. RB and JF have performed contract research work for the HPA on behalf of Pfizer, GSK, Sanofi Pasteur MSD, Novartis Vaccines and Merck. SNL, MPS, JSF and JF have received assistance for attending conferences from Pfizer and GSK. All other authors: no conflict of interest. 


\section{References}

1. Ladhani SN. Two decades of experience with the Haemophilus influenzae serotype b conjugate vaccine in the United Kingdom. Clin Ther. 2012;34(2):385-99.

2. Swingler G, Fransman D, Hussey G. Conjugate vaccines for preventing Haemophilus influenzae type B infections. Cochrane Database Syst Rev. 2007;(2):CDo01729.

3. Heath PT, Booy R, Azzopardi HJ, Slack MP, Bowen-Morris J, $\mathrm{Griffiths} \mathrm{H}$ et al. Antibody concentration and clinical protection after Hib conjugate vaccination in the United Kingdom. JAMA. 2000;284(18):2334-40.

4. McVernon J, Trotter CL, Slack MP, Ramsay ME. Trends in Haemophilus influenzae type b infections in adults in England and Wales: surveillance study. BMJ. 2004;329(7467):655-8.

5. Ramsay ME, McVernon J, Andrews NJ, Heath PT, Slack MP. Estimating Haemophilus influenzae type b vaccine effectiveness in England and Wales by use of the screening method. J Infect Dis. 2003;188(4):481-5.

6. McVernon J, Andrews N, Slack MP, Ramsay ME. Risk of vaccine failure after Haemophilus influenzae type b (Hib) combination vaccines with acellular pertussis. Lancet. 2003;361(9368):1521-3.

7. Anonymous. Laboratory reports of Haemophilus influenzae by age group and serotype, England and Wales, fourth quarter 2010 (and 2009). Health Protection Reports 2011; 5: 6-7.

8. Osborne K, Gay N, Hesketh L, Morgan-Capner P, Miller E. Ten years of serological surveillance in England and Wales: methods, results, implications and action. Int J Epidemiol. 2000;29(2):362-8.

9. Pickering JW, Martins TB, Schroder MC, Hill HR. Comparison of a multiplex flow cytometric assay with enzyme-linked immunosorbent assay for auantitation of antibodies to tetanus, diphtheria, and Haemophilus influenzae Type b. Clin Diagn Lab Immunol. 2002;9(4): 872-6.

10. Anderson P. The protective level of serum antibodies to the capsular polysaccharide of Haemophilus influenzae type b. J Infect Dis. 1984;149(6):1034-5.

11. Eskola J, Ward J, Dagan R, Goldblatt D, Zepp F, Siegrist CA. Combined vaccination of Haemophilus influenzae type $b$ conjugate and diphtheria-tetanus-pertussis containing acellular pertussis. Lancet. 1999;354 (9195):2063-8.

12. Kayhty H, Peltola H, Karanko V, Makela PH. The protective level of serum antibodies to the capsular polysaccharide of Haemophilus influenzae type b. J Infect Dis. 1983;147(6): 1100.

13. Kayhty $H$. Difficulties in establishing a serological correlate of protection after immunization with Haemophilus influenzae conjugate vaccines. Biologicals. 1994;22(4):397-402.

14. Fernandez J, Levine OS, Sanchez J, Balter S, LaClaire L, Feris J et al. Prevention of Haemophilus influenzae type b colonization by vaccination: correlation with serum anti-capsular IgG concentration. J Infect Dis. 2000;182(5):1553-6.

15. Goldblatt D, Hussain M, Andrews N, Ashton L, Virta C, Melegaro A et al. Antibody responses to nasopharyngeal carriage of Streptococcus pneumoniae in adults: a longitudinal household study. J Infect Dis. 2005;192(3):387-93.

16. Trotter CL, McVernon J, Andrews NJ, Burrage M, Ramsay ME. Antibody to Haemophilus influenzae type $b$ after routine and catch-up vaccination. Lancet 2003;361 (9368):1523-4.

17. McVernon J, Ramsay ME, McLean AR. Understanding the impact of Hib conjugate vaccine on transmission, immunity and disease in the United Kingdom. Epidemiol Infect. 2008;136(6):800-12.

18. Anonymous. Quarterly vaccination coverage statistics for children aged up to five years in the UK (COVER programme): January to March 2011. Health Protection Reports 2011; 5: 9-13.

19. Avery OT, Goebel WF. Chemo-immunological studies on the soluble specific substance of pneumococcus : I. The isolation and properties of the acetyl polysaccharide of pneumococcus type I. J Exp Med. 1933;58(6):731-55.

20. Schlesinger Y, Granoff DM. Avidity and bactericidal activity of antibody elicited by different Haemophilus influenzae type b conjugate vaccines. The Vaccine Study Group. JAMA. 1992;267(11): 1489-94.

21. Snape MD, Kelly DF, Salt P, Green S, Snowden C, Diggle L et al. Serogroup C meningococcal glycoconjugate vaccine in adolescents: persistence of bactericidal antibodies and kinetics of the immune response to a booster vaccine more than 3 years after immunization. Clin Infect Dis. 2006; 43(11):1387-94.

22. Kauppi M, Saarinen L, Kayhty H. Anti-capsular polysaccharide antibodies reduce nasopharyngeal colonization by Haemophilus influenzae type b in infant rats. J Infect Dis. 1993;167(2):365-71.
23. Anderson P, Johnston RB Jr, Smith DH. Human serum activities against Hemophilus influenzae, type b. J Clin Invest. 1972;51(1):31-8.

24. Anderson P, Pichichero ME, Insel RA. Immunogens consisting of oligosaccharides from the capsule of Haemophilus influenzae type b coupled to diphtheria toxoid or the toxin protein CRM197. J Clin Invest. 1985;76(1):52-9.

25. Leino T, Auranen K, Makela PH, Kayhty H, Takala AK. Dynamics of natural immunity caused by subclinical infections, case study on Haemophilus influenzae type b (Hib). Epidemiol Infect. 2000; 125(3):583-91.

26. Ladhani S, Slack MP, Heys M, White J, Ramsay ME. Fall in Haemophilus influenzae serotype b (Hib) disease following implementation of a booster campaign. Arch Dis Child. 2008;93(8):665-9.

27. Bar-On ES, Goldberg E, Fraser A, Vidal L, Hellmann S, Leibovici L. Combined DTP-HBV-HIB vaccine versus separately administered DTP-HBV and HIB vaccines for primary prevention of diphtheria, tetanus, pertussis, hepatitis $B$ and Haemophilus influenzae B (HIB). Cochrane Database Syst Rev. 2009;(3):CDo05530.

28. Schmitt HJ, Zepp F, Muschenborn S, Sumenicht G, Schuind $A$, Beutel K et al. Immunogenicity and reactogenicity of a Haemophilus influenzae type $b$ tetanus conjugate vaccine when administered separately or mixed with concomitant diphtheria-tetanus-toxoid and acellular pertussis vaccine for primary and for booster immunizations. Eur J Pediatr. 1998;157(3):208-14.

29. Kitchin NR, Southern J, Morris R, Hemme F, Thomas S, Watson MW et al. Evaluation of a diphtheria-tetanus-acellular pertussis-inactivated poliovirus-Haemophilus influenzae type b vaccine given concurrently with meningococcal group $C$ conjugate vaccine at 2, 3 and 4 months of age. Arch Dis Child. 2007;92(1):11-6.

30. Borrow R, Andrews N, Findlow H, Waight P, Southern J, Crowley-Luke $A$ et al. Kinetics of antibody persistence following administration of a combination meningococcal serogroup $C$ and haemophilus influenzae type b conjugate vaccine in healthy infants in the United Kingdom primed with a monovalent meningococcal serogroup $C$ vaccine. Clin Vaccine Immunol. 2010;17(1):154-9. 
